\title{
The Effect of Preoperative Video-assisted Patient Education on Postoperative Activities of Daily Living and Quality of Life in Patients with Femoral Fracture
}

\author{
Sevgi Vermisli Peker ${ }^{1}$, Emel Yılmaz ${ }^{2}$, Hakan Baydur ${ }^{3}$
}

\author{
${ }^{1}$ Manisa Celal Bayar University, \\ Institute of Health Science, \\ Department of Surgical Nursing, \\ Manisa, Turkey \\ ${ }^{2}$ Manisa Celal Bayar University, \\ Faculty of Health Science, \\ Department of Surgical Nursing, \\ Manisa, Turkey \\ ${ }^{3}$ Manisa Celal Bayar University, \\ Faculty of Health Science, \\ Department of Social Work, Manisa, \\ Turkey
}

\section{Correspondence:}

Emel Yilmaz

Address: Manisa Celal Bayar University, Faculty of Health

Science, Department of Surgical Nursing, Manisa, Turkey

Email: emelyilmazcbu@gmail.com

Received: 19.08.2019,

Accepted: 02.03 .2020

https://doi.org/10.5799/jcei/7844

\begin{abstract}
Objectives: The aim of study was to determine the effect of preoperative education on the postoperative activities of daily living and quality of life (QoL) of patients with trochanteric femoral fracture (TFF) treated with internal fixation.

Materials and methods: The patients were included those treated for TFF at an orthopaedic clinic in western Turkey between March and July 2014 in this randomised controlled study. The study was conducted in accordance with the Helsinki Declaration and was approved by the Ethics Committee of our university. The 56 patients were randomly divided into two groups. The intervention group was included in a preoperative education programme which is consisting of video-assisted oral presentation and education booklet, 1 day before surgery. At the end of education, one each sample of booklet and video were given to patients. The control group was informed with only routine clinical information by nurses. Data were collected using patient information form, Barthel Index (Bl), Harris Hip Score (HHS) and ShortForm Health Survey (SF-36). Descriptive statistics, Student's t-test, the Mann-Whitney U test, and a chi-square test were used to evaluate the data.
\end{abstract}

Results: Age, sex, educational level and length of hospital stay were similar in both groups $(p>0.05)$. Total HHS, BI, and SF-36 scores at 1 and 3 months postoperatively were higher the intervention group than the control group $(p<0.05)$.

Conclusion: Video-assisted preoperative education improves QoL and activities of daily living, in patients with TFF treated by nailing. An education programme like this could be useful for all surgical clinics.

Keywords: activities of daily living, patient education, quality of life, femoral fractures, videotape

\section{INTRODUCTION}

As a result of changes in the health care system and developments in medical science, the average lifespan of humans has increased significantly [1]. However, the incidence of chronic diseases in the elderly has also increased, resulting in longer durations of hospitalisation and recovery, and a decreased quality of life (QoL) [2]. In adults aged over 65 years, there is a high incidence of osteoporotic fractures. Moreover this end up with restricted activity and reduced QOL in elderly. Trochanteric femoral fractures (TFFs) in the elderly are caused by traumas, such as falls, but they can also occur in young adults, usually as a result

of severe traumas such as traffic accidents or falling from a height. In fractures, loss of health-related quality of life and physical capacity, reduced participation in activities of daily living are all potential outcomes for older adults [3]. In both groups, treatment and recovery are prolonged processes that require competent teamwork among clinical practitioners involved in the patient's treatment. During these processes, patient care and education delivered by nurses have important roles [4].

Appropriate patient education can eliminate existing or potential problems, and support patients in developing sustainable health behaviours. The acquisition of
} 
healthy behaviours has been examined in several multidisciplinary studies $[5,6]$. In litetature, most pointed to the effects of patient education, including with respect to the location of the educational institutions, duration of the education, and the type of educational materials provided $[7,8]$. Thorough preoperative education of the patient could possibly lead to an improvement of postoperative quality of life [9].

Patient education in surgical clinics has a positive effect on the course of the disease and increases the quality of life of the patients. Therefore, it is necessary to increase the diversity of patient education materials and to increase patient education [10]. In preoperative education, it is recommended to use multimedia support for training and counseling [11]. The video-assisted patient education is more advantage compared with written or verbally presented education. Audio-visual material can be entertaining and can also be used by those who have limited literacy and information stored on data carriers has the advantage of being repeatable [12-14]. Preoperative oral information can be forgotten during discharge and may prevent patients from feeling safe [15]. A multimedia education module can be improved patient satisfaction and can be provide better retention of information about surgery procedure in surgery patients [16]. Having training materials at the end of training that people can look at and watch over and over again can help to understand technically complex procedures $[11,12]$. It is stated that video-assisted training will be useful in providing easy-to-understand information for the participants living at a distance from the health center [17]. If the patients perceive their disease and surgical procedure which was performed and postoperative process, postoperative QOL can be better. Video-assisted patient education is the best way for this [18].

In Turkey, there have been few clinical studies on the education of patients scheduled for nailing surgery for TFF, in terms of postoperative daily activities and QoL. Thus, in this study, we examined the effectiveness of preoperative video-assisted education in terms of promoting postoperative activities of daily living and QoL in this group of patients. Our results may guide future studies on this topic.

\section{METHODS}

\section{Study Design and Sample}

This randomised controlled study was performed between March 2014 and July 2014 in the orthopaedics and traumatology clinic of a hospital in western Turkey. The research protocol was developed using a multidisciplinary approach that included input from the perioperative team.

The sample size was calculated based on Short-Form Health Survey (SF-36) scores, as previously described [19]. The study required a minimum sample size of 22 (11 patients receiving the intervention and 11 controls), given a power of $80 \%$, an $\alpha$ of 0.01 , and a $95 \%$ confidence level.
The information of number of TFF with inpatient in a year to orthopaedic clinic was obtained from clinical statistics (the number of patients in the last year was 215). In research process totally 109 patients were hospitalized due to TFF. Of the initial 88 patients deemed eligible for the study, 15 did not meet the inclusion criteria, 4 did not provide consent, 5 were treated conservatively, and 4 underwent total hip prosthesis. Patients were divided into two groups using block randomisation. Random numbers table was used in the selection of the patients. The flow diagram in Figure 1 shows the rate of attrition, including postoperatively excluded cases. In total, 56 patients completed the study (Figure 1).

\section{Inclusion Criteria}

Patients included in the study were those who (1) underwent total hip arthroplasty, (2) were oriented to person, place, and time, (3) could speak and understand Turkish, (4) were able to complete the questionnaire, (5) provided voluntary consent, and (6) were aged $>18$ years.

\section{Measures}

The data were collected using a patient information form, the Barthel Index (BI), the Harris Hip Score (HHS), and the SF-36.

- Patient information form: This form included questions regarding the socio-demographic characteristics of the patients, TFF risk factors, and the presence of any systemic diseases.

- BI: Developed in 1965 by Mahoney and Barthel, the BI assesses the level of independence in, and performance of, activities of daily living. The validity and reliability of the Turkish version of the index were determined by Kucukdeveci et al. (2000). Possible scores on the BI range from 0 to 100, with 0 corresponding to complete dependence and 100 to complete independence [20].

- HHS: Pain, physical function, deformity and range of motion constitute the four sub-categories of the HHS. The maximum total score is 100 points $(0-40=$ poor function, $41-$ 60 intermediate, $61-70=$ good, $71-85=$ very good, and $86-100$ $=$ excellent). The validity and reliability of the Turkish version of the HHS were determined by Celik et al. (2012) [21].

- SF-36: SF-36 which was developed by the Rand Corporation in 1992 is a quality of life scale most commonly used in the world and this form is known as the Short Form 36 in Turkey. The validity and reliability of the Turkish version of the SF-36 were determined by Kocyigit et al. (1999). The 36 items include eight subscales: physical function, physical state, bodily pain, general health, vitality, social functioning, emotional state, and mental health. These are scored between 0 and 100, with 0 being the worst possible health status and 100 the best. From these eight domains, two summary scores, pertaining to the physical and mental components of health, are calculate [22]. The calculation was performed with SPSS SPSS software.

\section{Education Programme}

The preoperative education programme is consisted of video-assisted oral presentation and an education booklet. 


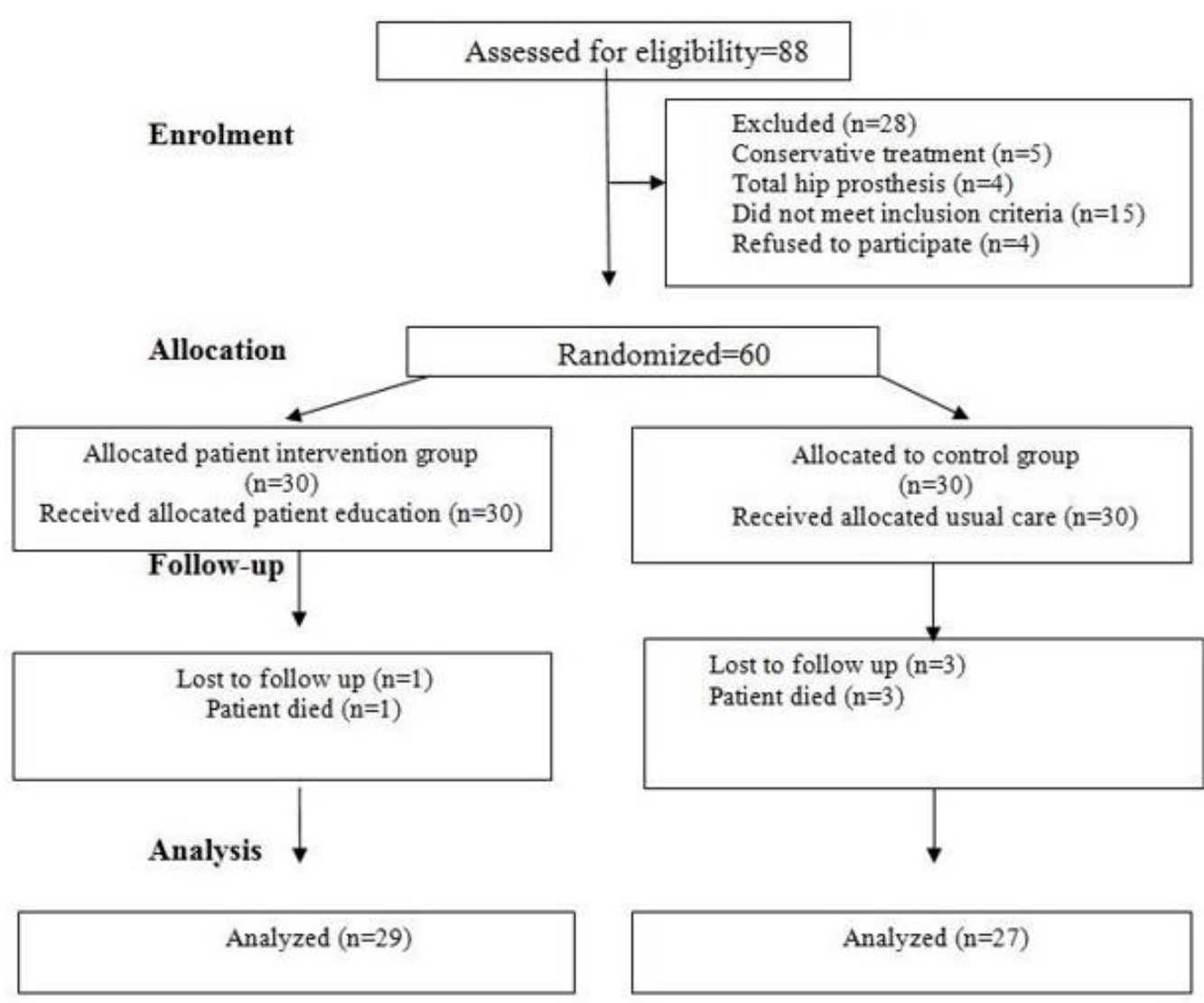

Figure 1. Consort flow study diagram

The video includes breathing and coughing exercises and post-operative foot and leg exercises, and is an 11-minute video. Video shoot was done by researchers. The exercises in the video were arranged with the opinion of an orthopedics and physiotherapy specialist. For the narrations in the video, the scenario was prepared before shooting and the videos were recorded in accordance with this scenario. There was no professional help for the video footage, but support from a local media employee to edit it. In the education booklet, information about the preoperative, intraoperative, postoperative and post-discharge procedures and the exercises in the video are presented in visual and written form. The education booklet, which is organized with the subject area of contents, is in A5 page layout and consists of a total of 56 pages. At the bottom of each page, there was a space where patients could write questions they might want to ask researchers about the subject. At the end of the education, one each sample of booklet and video were given to patients. In the video and education booklet, a narrative language was used which could be understood by the patients and their relatives. As this is a thesis study the adequacy of the educational materials was examined and approved by the academicians who are in the thesis followup jury. In addition, education materials were tested with watching and reading by 10 volunteer patients (exept research participants) before the start study. They reported that education materials are understandable.

\section{Procedure}

The day before surgery, patients were asked to fill out the patient information form, the SF-36, and the BI. The intervention group received both routine education and visual materials in a 45-min oral and visual presentation that prepared them for surgery (including general information about the femoral trochanter fracture, requirements before surgery, etc.); also, the surgical procedure to be performed the next morning was explained, including anaesthesia, and information was provided on the post-operative healing process (nutrition, pain management, etc.) and home care and recovery (activities of daily living, home security, use of medication, etc.). After the education session, the patients and/or their relatives were given a booklet and an educational $C D$, prepared by the researchers, for use as a reference. The control group received routine standard education in the clinic. At 1 and 3 months after surgery, the patients were invited to the clinic for follow-up, at which time they were asked to complete the HHS, SF-36, and BI.

\section{Research Ethics}

The study was practiced in accordance with the Helsinki Declaration and was approved by the Ethics Committee of Celal Bayar University (reference number: 26/01/2014/20478486-133). Informed, written consent was obtained from each patient. 
Preoperative education on femoral fractures

Table 1. Demographic characteristics of patients

\begin{tabular}{|c|c|c|c|c|c|}
\hline \multirow{2}{*}{ Characteristics } & & Intervention Group (n=29) & Control Group (n=27) & \multirow{2}{*}{$z, \chi^{2}, \mathrm{t}$} & \multirow{2}{*}{$p$ value } \\
\hline & & Mean \pm SD or Median (IQR) & Mean \pm SD or Median(IQR) & & \\
\hline Age (years) & & $75.0(60.0-79.5)$ & $75.0(63.0-82.0)$ & $\mathrm{z}=0.238^{\mathrm{a}}$ & 0.812 \\
\hline $\mathrm{BMI}\left(\mathrm{kg} / \mathrm{m}^{2}\right)$ & & $26.7(23.4-28.6)$ & $22.7(20.8-25.0)$ & $z=-3.248^{a}$ & 0.001 \\
\hline \multirow{2}{*}{ Gender } & Female & $17(50.0)$ & $17(50.0)$ & \multirow{2}{*}{$\chi^{2}=0.111^{b}$} & \multirow{2}{*}{0.740} \\
\hline & Male & $12(54.5)$ & $10(45.5)$ & & \\
\hline \multirow{3}{*}{ Education level } & Literate/primary school & $21(50.0)$ & $21(50.0)$ & \multirow{3}{*}{$\chi^{2}=1.407^{b}$} & \multirow{3}{*}{0.704} \\
\hline & Secondary school & $3(75.0)$ & $1(25.0)$ & & \\
\hline & $\geq$ High school & $5(50.0)$ & $5(50.0)$ & & \\
\hline \multirow{2}{*}{$\begin{array}{l}\text { Trochanteric } \\
\text { fracture location }\end{array}$} & Right & $7(29.2)$ & $17(70.8)$ & \multirow{2}{*}{$\chi^{2}=8.606^{b}$} & \multirow{2}{*}{0.003} \\
\hline & Left & $22(68.8)$ & $10(31.2)$ & & \\
\hline \multirow{2}{*}{ Fracture cause } & Simple fall & $26(53.1)$ & $23(46.9)$ & \multirow{2}{*}{$\chi^{2}=0.700^{b}$} & \multirow{2}{*}{0.459} \\
\hline & Other injuries & $3(42.9)$ & $4(57.1)$ & & \\
\hline \multicolumn{2}{|c|}{ Length of hospital stay/ day } & $9.5 \pm 3.2(3-15)$ & $10.9 \pm 3.5(5-21)$ & $t=-1.531^{c}$ & 0.132 \\
\hline
\end{tabular}

Abbreviations: $\mathrm{BMI}=$ body mass index, IQR= Interquartile Range ${ }^{\mathrm{a}}$ Mann Whitney $\mathrm{U}$ test, ${ }^{\mathrm{b}} \mathrm{Chi}$ Square test, ${ }^{\mathrm{c}}=$ Student $\mathrm{t}$-test

Table 2. Preoperative SF-36 and Barthel Index Scores

\begin{tabular}{|c|c|c|c|c|}
\hline \multirow{2}{*}{ Scores } & InterventionGroup ( $n=29)$ & Control Group ( $n=27)$ & \multirow{2}{*}{$z, t$} & \multirow{2}{*}{$p$ value } \\
\hline & Median(IQR) & Median(IQR) & & \\
\hline Barthel Index & $20.0(15.0-32.5)$ & $20.0(15.0-30.0)$ & $-0.715^{a}$ & 0.415 \\
\hline Physical functioning & $0.0(0.0-0.0)$ & $0.0(0.0-0.0)$ & $-1.377^{a}$ & 0.169 \\
\hline Role-physical & $0.0(0.0-0.0)$ & $0.0(0.0-0.0)$ & $-0.162^{a}$ & 0.871 \\
\hline Bodily pain & $22.0(22.0-26.50)$ & $22.0(12.0-22.0)$ & $-1.314^{a}$ & 0.189 \\
\hline Role-emotional & $20.0(0.0-16.7)$ & $0.0(0.0-0.0)$ & $-0.820^{a}$ & 0.412 \\
\hline Vitality & $35.0(25.0-47.5)$ & $35.0(25.0-50.0)$ & $-0.288^{a}$ & 0.773 \\
\hline \multirow[t]{2}{*}{ Social functioning } & $25.0(12.5-25.0)$ & $12.5(0.0-25.0)$ & $-1.871^{a}$ & 0.061 \\
\hline & Mean \pm SD & Mean \pm SD & & \\
\hline General health & $42.5 \pm 17.7$ & $53.3 \pm 17.6$ & $-2.288^{b}$ & 0.026 \\
\hline Mental health & $55.0 \pm 16.2$ & $51.0 \pm 20.0$ & $0.810^{b}$ & 0.425 \\
\hline Physical component summary & $23.0 \pm 2.8$ & $24.9 \pm 4.2$ & $-1.989^{b}$ & 0.052 \\
\hline Mental component summary & $38.8 \pm 7.1$ & $37.4 \pm 8.9$ & $0.597^{b}$ & 0.553 \\
\hline
\end{tabular}

Abbreviations: SD = standard deviation, IQR = Interquartile Range should be added, ${ }^{a}$ Mann Whitney U test, ${ }^{b}$ Student t-test

\section{Analysis}

The data were analysed using SPSS software (ver. 15.0; SPSS Inc., Chicago, IL, USA). The Kolmogorov Smirnov test was performed to determine the normality of the data. Numerical variables are expressed as mean \pm standard deviation or as the median (interquartile range), and categorical variables as number and percent. The data of the two groups were compared using Student's t-test, the MannWhitney U-test, chi-square test, or Fisher's exact test. A $p$ value $<0.05$ was considered to indicate statistical significance.

\section{RESULTS}

The demographic characteristics of the study population are shown in Table 1. The median age and body mass index (BMI) of the patients in the intervention group was 75.0 years and $26.7 \mathrm{~kg} / \mathrm{m}^{2}$, respectively. BMI $(z=-3.248, p=0.001)$, but not age $(z=-0.238, p=0.812)$, was significantly different between the two groups, with patients in the intervention group having a higher BMI than those in the control group. More than half of the patients in the intervention group (54.5\%) were male, $75 \%$ were secondary school graduates, and $51.8 \%$ had not received prior information about the surgery. There was no statistically significant difference in the sex distribution, educational level, or fracture site and length of hospital stay between the intervention and control groups ( $p>0.05)$.

Table 2 shows the preoperative SF-36 and BI scores of the patients in the intervention and control groups. Before surgery, the differences in BI and subscale SF-36 scores were not significantly different between the two groups $(p>0.05)$, 
Preoperative education on femoral fractures

Table 3. The first month postoperative SF-36, Barthel Index and Harris Hip Scores

\begin{tabular}{|c|c|c|c|c|}
\hline \multirow{2}{*}{ Scores } & Intervention Group (n=29) & Control Group (n=27) & \multirow{2}{*}{$z, t$} & \multirow{2}{*}{$p$ value } \\
\hline & Median(IQR) & Median(IQR) & & \\
\hline Barthel Index & $52.5(35.0-70.0)$ & $30.0(30.0-50.0)$ & $-3.185^{a}$ & 0.001 \\
\hline Harris Hip score & $51.8(39.7-58.6)$ & 21.2(17.4-34.1) & $-5.182^{a}$ & 0.000 \\
\hline Physical functioning & $50.0(45.0-50.0)$ & $30.0(25.0-40.0)$ & $-6.199^{a}$ & 0.000 \\
\hline Role-physical & $75.0(37.5-75.0)$ & $50.0(25.0-50.0)$ & $-2.448^{a}$ & 0.014 \\
\hline Bodily pain & $52.0(41.0-74.0)$ & $22.0(12.0-31.0)$ & $-5.258^{a}$ & 0.000 \\
\hline Role-emotional & $100.0(16.7-100.0)$ & $33.3(0.0-66.7)$ & $-2.229^{a}$ & 0.026 \\
\hline Vitality & $55.0(47.5-65.0)$ & $25.0(15.0-45.0)$ & $-4.502^{a}$ & 0.000 \\
\hline \multirow[t]{2}{*}{ Social functioning } & $62.5(50.0-75.0)$ & $25.0(12.5-50.0)$ & $-4.129^{a}$ & 0.000 \\
\hline & Mean \pm SD & Mean \pm SD & & \\
\hline Physical component summary & $39.1 \pm 4.3$ & $31.6 \pm 3.6$ & $7.113^{b}$ & 0.003 \\
\hline Mental component summary & $47.0 \pm 7.1$ & $37.5 \pm 5.5$ & $5.529^{b}$ & 0.000 \\
\hline General health & $62.4 \pm 17.5$ & $48.1 \pm 17.4$ & $3.063^{b}$ & 0.000 \\
\hline Mental health & $68.0 \pm 12.8$ & $48.6 \pm 12.7$ & $5.688^{b}$ & 0.000 \\
\hline
\end{tabular}

Abbreviations: $\mathrm{SD}=$ standard deviation, $\mathrm{QR}=$ Interquartile Range should be added, ${ }^{a}$ Mann Whitney U test, ${ }^{b}$ Student t-test

Table 4. The third month postoperative SF-36, Barthel Index and Harris Hip Scores

\begin{tabular}{|c|c|c|c|c|}
\hline \multirow{2}{*}{ Scores } & Intervention Group (n=29) & Control Group ( $n=27)$ & \multirow{2}{*}{$z, t$} & \multirow{2}{*}{$p$ value } \\
\hline & Median(IQR) & Median(IQR) & & \\
\hline Barthel Index & $90.0(90.0-95.0)$ & $60.0(40.0-85.0)$ & $-4.335^{a}$ & 0.000 \\
\hline Harris Hip Score & 95.3(91.2-99.5) & $52.0(42.2-68.8)$ & $-6.003^{a}$ & 0.000 \\
\hline Mental component summary & $57.0(54.4-59.2)$ & $42.2(35.8-49.0)$ & $-5.813^{a}$ & 0.000 \\
\hline General health & $87.0(77.0-94.5)$ & $52.0(30.0-70.0)$ & $-4.990^{a}$ & 0.000 \\
\hline Mental health & $84.0(80.0-88.0)$ & $56.0(40.0-64.0)$ & $-5.286^{a}$ & 0.000 \\
\hline Physical functioning & $65.0(50.0-75.0)$ & $30.0(25.0-40.0)$ & $-4.376^{a}$ & 0.000 \\
\hline Role-physical & $100.0(75.0-100.0)$ & $50.0(25.0-100.0)$ & $-2.877^{a}$ & 0.004 \\
\hline Bodily pain & $84.0(74.0-100.0)$ & $51.0(41.0-52.0)$ & $-5.752^{a}$ & 0.000 \\
\hline Role-emotional & $100.0(100.0-100.0)$ & $33.3(0.0-100.0)$ & $-3.923^{a}$ & 0.000 \\
\hline \multirow[t]{2}{*}{ Social functioning } & $87.5(75.0-87.5)$ & $50.0(25.0-62.5)$ & $-6.237^{a}$ & 0.000 \\
\hline & Mean \pm SD & Mean \pm SD & & \\
\hline Vitality & $48.2 \pm 13.8$ & $35.9 \pm 18.9$ & $7.556^{b}$ & 0.000 \\
\hline Physical component summary & $71.4 \pm 5.7$ & $38.1 \pm 7.3$ & $7.090^{b}$ & 0.000 \\
\hline
\end{tabular}

Abbreviations: SD = standard deviation, QR= Interquartile Range should be added, ${ }^{a}$ Mann Whitney U test, ${ }^{b}$ Student t-test

with the exception of the preoperative SF-36 general health subscale score $(p<0.05)$.

Table 3 shows the HHS, SF-36, and BI scores of the intervention and control groups at 1 month after surgery. There was a statistically significant difference between groups in scores on all subscales of the SF-36, and in the HHS and BI scores $(p<0.05)$; consistently higher scores were seen in the patients in the intervention group versus the control group.

The SF-36, HHS, and BI scores of the intervention and control groups at 3 months after surgery are shown in Table 4. The scores on all SF-36 subscales, as well as the HHS and
BI scores were significantly higher in the intervention than in the control group (Table 4).

\section{DISCUSSION}

Hip fractures are common in the elderly and rehabilitation is long and costly. Failure to provide effective treatment and rehabilitation may result in an inability to perform activities of daily living, forcing the patient to continue life as a dependent, and thus to experience the associated complications and a reduced QoL $[2,19]$.

Most of the patients in our study were aged above 65 years. The results are consistent with those previously reported in the literature [2,23]. Overall, more than half of the participants in our study were female, similar to previous 
studies [24,25]. Taken together, the findings indicate a higher incidence of hip fracture in women than in men. Although some studies found that patients with a high BMI are more prone to hip fractures $[22,25]$, most of our patients were of normal weight. However, it has also been suggested that a high BMI increases bone mineral density and thus reduces the risk of hip fracture [26]. The most common cause of hip fracture in our study group was a simple fall. In the series of Liu et al. (2015), most of the patients had suffered a hip fracture from a simple fall, whereas most of the patients in the study of Wang et al. (2015) had a low-energy trauma $[27,28]$. In our patients, the fracture occurred more often in the left than in the right hip. Hartford \& Knowles (2016) was reported that more than half of their patients, the fracture involved the right hip [29], whereas Sahin et al. (2014) was reported that most of the patients had fractures of the left hip [30]. Since most people are right-handed, during a fall or accident the left limbs may be less protected. Therefore, hip fracture would more frequently involve the left rather than the right side [31].

Patients and relatives are preoperatively informed for surgery by the treating physician in clinic routine. However, detailed information about the surgery is may not usually given $[1,4]$. Planned, systematic patient education can accelerate the healing process, minimise pain and anxiety, shorten the length of hospital stay, reduce disease complications, lower hospitalisation costs, and avoid repeated hospital admission. It can also improve patient selfcare ability and QoL $[5,32,33]$. On the other hand, the need to treat large numbers of patients, as is the case in Turkey, inevitably hinders the ability of nurses to offer in-depth patient education. In addition to willingness and knowledge of nurses, patient education requires a higher nurse: patient ratio. In Turkey, the number of doctors and nurses in public hospitals quite lack of but too many patient are treated and cared. The usual information process of the patient is run by surgeons and nurses, and it may be insufficient due to time pressure in the everyday hospital environment and lack of experience. When adequate and effective time for training is not available, video-assisted visual and auditory information could be seen as an effective education method and this model is could be both time-saving and cost-effective method.

For some surgical protocols, short videos provided with visual materials may better communicate important points and difficult concepts, help patients and relatives of the patient to focus education. The most important common point in the education process of the patient is that it is appropriate and understandable to the level of health literacy of the society [13]. In our study, patients of the video-assisted education group reported that they found the video presentation and patient education booklet quite explicit and easy to understand. The video clip gave clear answers to common questions about breathing and coughing exercises and foot and leg exercises. The education booklet gave clear answers to questions about the important points that patients should know about trochanteric femoral fracture and PFNA surgery. Videos that show that real people are doing something, rather than videos with health information presented only verbally or visually, are reported to be more effective in changing patient behavior [12]. In our study, the information in the video content was role played by the researchers.

In a systematic review which was about that preoperative patient education and its effects on postoperative patient outcomes, the measurement of outcomes such as patients' cognitive, experiential and bio-physiological aspects was emphasized [32]. The measurement tools used in our study are important for evaluate postoperative effects of preoperative training, and widely used.

In a randomized controlled study, video education (both written and verbal information) was given preoperatively in arthroscopic shoulder surgery by Hoppe et al. (2015) and it was found that information in the form of videos, provided before surgery, was more useful than a standard education program [7]. Preoperative education was found to be more effective for postoperative pain control, reduced the risk of hip dislocation within 6 months, and had positive effects on early discharge, postoperative anxiety, pain, heart rate and blood pressure [8]. In few studies performed to examine of the effects of preoperative education on postoperative activities of daily living and QoL, preoperative patient education given by nurses increased QoL scores and decreased the length of hospitalisation in patients operated on for hip fracture $[2,25,34]$. In our study, there was no difference between the groups in terms of length of hospital stay however we did not evaluate postoperative anxiety, pain, heart rate and blood pressure.

It is stated that patients who received multimedia supported training the day before surgery had higher satisfaction and had less anxiety about the operation [15]. An addition, patients' level of understanding the given information is better and the informed consent process is completed in a shorter time [15]. Crabtree et al. (2012) found that video-based education about of surgical procedure was given preoperatively for patients undergoing pulmonary resection, reduced patients' anxiety and increased overall patient satisfaction [29]. Patients' satisfaction and anxiety levels were not evaluated in our study. However, it can be predicted that the anxiety levels of the patients who are included in the training program and who have the opportunity to communicate more frequently with the researcher and who receive adequate training will decrease. It is reported that there is a negative relationship between quality of life and anxiety level [36]. It can be said that this process increases patient satisfaction and patient compliance and thus postoperative quality of life is higher than the control group. 
The healing of a hip fracture in a patient with an osteoporotic proximal femur was shown to depend largely on the patient's preoperative health status and pre-functional ability [37]. In this study, the condition of the patients prior to the fracture was not known, since the patients were enrolled after hospitalisation. However, both groups of patients had low scores of SF-36 subscale and BI preoperatively, and was no statistically significant difference.

After hip and knee surgery, the physical activity level of patients increases month by month, and at 2 years after surgery nearly half of all patients treated for hip fracture are able to return to daily life activities at the pre-fracture level [38]. Patient education prior to hip replacement surgery was shown to improve activities of daily living in $83 \%$ of patients [2]. It has been reported that patients who received preoperative education had HHS scores at month 2 that were higher than those of the control group [36,39]; this is in agreement with our findings. In our study, at months 1 and 3 after surgery, the SF-36, BI and HHS scores were significantly higher in the intervention group than in the control group. Within 6 weeks after surgery, our patients returned to their daily activities and their SF-36 subscale scores increased. Similar to our study results, in other studies after 45 days and 3 months, scores on all subscales of the SF36 were significantly increased $[33,39]$. It was reported that the patients who underwent total knee prosthesis with preoperative video-assisted training were well fit to the exercise program during the first two weeks after discharge from the hospital, but then decreased their compliancelevels. Likewise, at six-month follow-up, on health-related quality of life outcomes and levels of activities of daily living were not significantly different in each groups [3]. It was determined in Zieren et al. (2007) that quality of life in patients who underwent inguinal hernia surgery and given preoperative video-assisted education was higher soon after surgery and until 3 months afterwards but no difference was detectable six months after surgery. In addition, it was stated that preoperative activities took place earlier in the video group [9]. Similar to literature, in our study SF-36 subscale scores of patients in the intervention and control groups increased during the first postoperative month compared to preoperatively, and during the third compared to the first postoperative month. The SF-36 subscale, BI and HHS scores were higher in the intervention group than in the control group at first and third months. However, despite the high scores of patients in the intervention group seen at month 3 in this study, further increases may not be occur due to the high average age of these patients.

Finally, our findings show that preoperative education enriched by supporting materials, such as audio-visual tools and booklets, significantly influences the healing process. The higher functional capacity and quality of life levels of the patients in the intervention group may be due to the fact that they can ask the researcher more questions as a result of the education they have received and that they have better adapted to the treatment process by reinforcing their knowledge and practicing more easily thanks to the information given in the education video. It can be said that the patients who have functional capacity improved with the training given with visual and audio (video-assisted) materials increase their ability to perform daily life activities and as a result their quality of life increases. Furthermore, the combination of effective preoperative patient education increases the active participation of patients in the healing process and can contribute to improvement of QoL with early functional gain.

\section{LIMITATIONS OF THE STUDY}

The limitations of this study include the nature of the study population, where the effects of education were examined only in patients with a diagnosis of TFF who were hospitalised and scheduled for surgery. Whether the same results would be obtained in other preoperative populations remains to be investigated. Also, because the instruments were completed during face-to-face interviews, the reliability of the data could not be confirmed, and nor could the degree of postoperative compliance with the education programs following discharge. Nonetheless, at 1 and 3 months after TFF nailing, patients who received preoperative education had superior outcomes in terms of activities of daily living and QoL than controls during the postoperative period.

\section{CONCLUSION}

Preoperative education that was given with videoassisted visual and auditory training materials provided by nurses to patients scheduled for TFF nailing resulted in a faster recovery, restoration of activities of daily living, and a good QoL during the postoperative period. To increase the efficiency of patient education, should use different educational materials such as videos and booklets prior to surgery is recommended. Our results provide guidance for health professionals involved in the treatment of patients with TFF by internal fixation.

\section{RELEVANCE TO CLINICAL PRACTICE}

Our results can facilitate restoration of QoL and activities of daily living after surgery, and are therefore of interest to health professionals working in surgical clinics. They also provide evidence of the positive effects of systematic preoperative patient education. Such studies can be a guide to future writing and help reorganize patient education materials on TFF surgery. Such studies can be a guide to future writing and help reorganize patient education materials on TFF surgery.

\section{ACKNOWLEDGEMENT}

The authors would like to thank to the nurses of the orthopedic clinic and surgeons for their cooperation.

Declaration of interest: The authors report no conflicts of interest.

Financial Disclosure: No financial support was received. 


\section{REFERENCES}

1. Ebrahimi H, Ashrafi Z, Rudsari DM, Parsayekta Z, Haghani $H$. Effect of family-based education on the quality of life of persons with type 2 diabetes: A randomized clinical trial. J Nurs Res. 2018;26(2):97-103. doi: 10.1097/jnr.0000000000000212.

2. Peeters CM, Visser E, Van de Ree CL, Gosens T, Den Oudsten BL, De Vries J. Quality of life after hip fracture in the elderly: A systematic literature review. Injury. 2016;47(7):1369-82. doi: 10.1016/j.injury.2016.04.018.

3. Haines TP, Russell T, Brauer SG, Erwin S, Lane P, Urry $\mathrm{S}$, Jasiewicz J, Condie P. Effectiveness of a video-based exercise programme to reduce falls and improve healthrelated quality of life among older adults discharged from hospital: A pilot randomized controlled trial. Clinical Rehabilitation. 2009;23(11):973-85. doi: 10.1177/0269215509338998

4. Leal J, Gray AM, Hawley S,et al. Cost-Effectiveness of orthogeriatric and fracture liaison service models of care for hip fracture patients: A population-based study. J Bone Miner Res. 2017;32(2):203-11. doi: 10.1002/ jbmr.2995.

5. Sinclair PM, Kable A, Levett-Jones T, Booth D. The effectiveness of Internet-based e-learning on clinician behaviour and patient outcomes: a systematic review. Int J Nurs Stud. 2016;57:70-81. doi: 10.1016/j.ijnurstu.2016. 01.011 .

6. Sadegh Tabrizi J, Seyedhejazi M, Fakhari A, Ghadimi F, Hamidi M, Taghizadieh N. Preoperative education and decreasing preoperative anxiety among children aged 8 10 years old and their mothers. Anesth Pain Med. 2015;5(4):e25036. doi: 10.5812/aapm.25036

7. Hoppe DJ, Denkers M, Hoppe FM, Wong IH. The use of video before arthroscopic shoulder surgery to enhance patient recall and satisfaction: a randomized-controlled study. J Shoulder Elbow Surg. 2014;23(6):e134-9. doi: 10.1016/j.jse.2013.09.008.

8. Klemetti S, Leino-Kilpi H, Cabrera E, et al. Difference between received and expected knowledge of patients undergoing knee or hip replacement in seven European countries. Clin Nurs Res. 2015;24(6):624-43. doi: 10.1177/1054773814549992.

9. Zieren J, Menenakos C, Mueller JM. Does an informative video before inguinal hernia surgical repair influence postoperative quality of life? Results of a prospective randomized study. Quality of Life Research. 2007;16(5):725-9. doi:10.1007/s11136-007-9171-y

10. Yildiz T. Current methods used in surgery patient education: Not disease centered, patient centered education. Clinical and Experimental Health Sciences. 2015;5(2):129-33. doi:10.5455/musbed.20150125115949
11. Ihrig A, Herzog W, Huber CG, Hadaschik B, Pahernik S, Hohenfellner M, Huber J. Multimedia support in preoperative patient education for radical prostatectomy: The physicians' point of view. Patient education and counseling. 2012;87(2):239-42. doi: 10.1016/j.pec.2011.08.014.

12. Abed MA, Himmel W, Vormfelde S, Koschack J. Videoassisted patient education to modify behavior: a systematic review. Patient education and counseling. 2014;97(1):16-22. doi: 10.1016/j.pec.2014.06.015

13. Fahey N, Patel V, Rosseau G. A comparative analysis of online education resources for patients undergoing endoscopic transsphenoidal surgery. World Neurosurgery. 2014;82(6):e671-5. doi: 10.1016/j.wneu. 2014.09.014

14. Erdogan Z, Bulut H. Effectiveness of Computer Assisted Training of Patients Undergoing Lumbar Disc Herniation Surgery. Turkish Neurosurgery. 2019. doi: 10.5137/1019-5149.JTN.26775-19.2

15. Zhang Y, Ruan X, Tang H, Yang W, Xian Z, Lu M. Video-assisted informed consent for cataract surgery: a randomized controlled trial. Journal of Ophthalmology. 2017; Article ID 9593631, 6 pages doi: $10.1155 / 2017 / 9593631$

16. Cornoiu A, Beischer AD, Donnan L, Graves S, de Steiger R. Multimedia patient education to assist the informed consent process for knee arthroscopy. ANZ journal of surgery. 2011;81(3):176-80. doi: 10.1111/j.14452197.2010.05487.x

17. Sonne SC, Andrews JO, Gentilin SM, Oppenheimer S, Obeid J, Brady K, Wolf S, Davis R, Magruder K. Development and pilot testing of a video-assisted informed consent process. Contemporary clinical trials. 2013;36(1):25-31. doi: 10.1016/j.cct.2013.05.011

18. Beamond BM, Beischer AD, Brodsky JW, Leslie H. Improvement in surgical consent with a preoperative multimedia patient education tool: a pilot study. Foot \& ankle international. 2009;30(7):619-26. doi: 10.3113/ FAI.2009.0619

19. Sendir M, Babadag K. The effect of patient education prior to hip replacement surgery on postoperative physical compliance and quality of life. Nursing Bulletin 2000; 12(46): 27-42.

20. Kucukdeveci AA, Yavuzer G, Tennant A, Süldür N, Sonel B, Arasil T. Adaptation of the modified Barthel Index for use in physical medicine and rehabilitation in Turkey. Scand J Rehabil Med. 2000;32(2):87-92.

21. Celik D, Can C, Aslan Y, Kerem B, Razak Ozdincler A. Translation and cultural adaptation of harris hip score into the Turkish. IN: XIVTH Development of Physiotherapy Congress Abstracts of Oral Presentations and Posters. Turkish J of Physiotherapy Rehabilitation. 2021;23(1):82. www.fizyoterapirehabilitasyon.org 
22. Kocyigit, H. Reliability and validity of the Turkish version of short form-36 (SF-36): a study in a group of patients will rheumatic diseases. Turk J Drugs Ther. 1999;12:102-6.

23. Maisongrosse $\mathrm{P}$, Lepage $\mathrm{B}$, Cavaignac $\mathrm{E}$, et al. Obesity is no longer a risk factor for dislocation after total hip arthroplasty with a double-mobility cup. Int Orthop. 2015;39(7):1251-8. doi: 10.1007/s00264-014-2612-7.

24. Cheung WH, Shen WY, Dai DL, et al. Evaluation of a multidisciplinary rehabilitation programme for elderly patients with hip fracture: A prospective cohort study. J Rehabil Med. 2018;50(3):285-91. doi: 10.2340/ 16501977-2310.

25. Sprague S, BhandariM, Heetveld MJ, Liew, et al. Factors associated with health-related quality of life, hip function, and health utility after operative management of femoral neck fractures. Bone Joint J. 2018;100(3):3619. doi: 10.1302/0301-620X.100B3.BJJ-2017-0853.R1.

26. Cawsey S, Padwal R, Sharma AM, Wang X, Li S, Siminoski K. Women with severe obesity and relatively low bone mineral density have increased fracture risk. Osteoporos Int. 2015;26(1):103-111. doi: 10.1007/ s00198-014-2833-z.

27. Liu LK, Lee WJ, Chen LY, et al. Association between frailty, osteoporosis, falls and hip fractures among community-dwelling people aged 50 years and older in Taiwan: results from I-Lan Longitudinal Aging Study. PLoS One. 2015;10(9):e0136968. doi: 10.1371/ journal.pone.0136968.

28. Wang $\mathrm{O}, \mathrm{Hu} \mathrm{Y}$, Gong S, Xue Q, et al. A survey of outcomes and management of patients post fragility fractures in China. Osteoporos Int. 2015;26(11):2631-40. doi: 10.1007/s00198-015-3162-6.

29. Hartford JM, Knowles SB. Risk factors for perioperative femoral fractures: cementless femoral implants and the direct anterior approach using a fracture table. J Arthroplasty. 2016;31(9):2013-8. doi: 10.1016/j.arth. 2016.02.045.

30. Sahin EK, Imerci A, Kınık H, Karapınar L, Canbek U, Savran A. Comparison of proximal femoral nail antirotation (PFNA) with AO dynamic condylar screws (DCS) for the treatment for unstable peritrochanteric femoral fractures. Eur J Orthop Surg Traumatol. 2014;24(3):347-52. doi: 10.1007/s00590-013-1195-0.
31. Kiyota T, Fujiwara K. Dominant side in single-leg stance stability during floor oscillations at various frequencies. J Physiol Anthropol. 2014;33:25. doi: 10.1186/18806805-33-25.

32. Ronco M, Iona L, Fabbro C, Bulfone G, Palese A. Patient education outcomes in surgery: a systematic review from 2004 to 2010. Int J Evid Based Healthc. 2012;10(4):30923. doi: 10.1111/j.1744-1609.2012.00286.x.

33. Tseng MY, Liang J, et al. Effects of interventions on trajectories of health-related quality of life among older patients with hip fracture: a prospective randomized controlled trial. BMC Musculoskelet Disord. 2016;17(1):114. doi: 10.1186/s12891-016-0958-2.

34. Siggeirsdottir K, Olafsson O, Jonsson H, Iwarsson S, Gudnason V, Jonsson BY. Short hospital stay augmented with education and home-based rehabilitation improves function and quality of life after hip replacement: randomized study of 50 patients with 6 months of follow-up. Acta Orthop. 2005 ;76(4):555-62.

35. Crabtree TD, Puri V, Bell JM, et al. Outcomes and perception of lung surgery with implementation of a patient video education module: a prospective cohort study. J Am Coll Surg. 2012;214(5):816-821.e2. doi: 10.1016/j.jamcollsurg.2012.01.047.

36. Gold M, Dunn LB, Phoenix B, Paul SM, Hamolsky D, Levine JD, Miaskowski C. Co-occurrence of anxiety and depressive symptoms following breast cancer surgery and its impact on quality of life. Eur. J. of Oncology Nurs. 2016;20:97-105. doi: 10.1016/j.ejon.2015.06.003

37. González-Zabaleta J, Pita-Fernandez S, Seoane-Pillado T, López-Calviño B, Gonzalez-Zabaleta JL. Dependence for basic and instrumental activities of daily living after hip fractures. Arch Gerontol Geriatr. 2015;60(1):66-70. doi: 10.1016/j.archger.2014.10.020.

38. de Groot IB, Bussmann HJ, Stam HJ, Verhaar JA. Small increase of actual physical activity 6 months after total hip or knee arthroplasty. Clin Orthop Relat Res. 2008;466(9):2201-8. doi: 10.1007/s11999-008-0315-3.

39. Czyżewska A, Glinkowski WM, Walesiak K, Krawczak K, Cabaj D, Górecki A. Effects of preoperative physiotherapy in hip osteoarthritis patients awaiting total hip replacement. Arch Med Sci. 2014 ;10(5):985-91. doi: 10.5114/aoms.2014.46218. 